\title{
USO DE GEOMANTAS NO CONTROLE DA EROSÃO SUPERFICIAL HÍDRICA EM UM TALUDE EM CORTE DE ESTRADA ${ }^{(1)}$
}

\author{
Leonardo Silva Fernandes ${ }^{(2)}$, James Jackson Griffith ${ }^{(3)}$, Dilermando \\ Miranda da Fonseca ${ }^{(4)}$, Luiz Eduardo Dias ${ }^{(5)} \&$ Hugo Alberto Ruiz ${ }^{(5)}$
}

\begin{abstract}
RESUMO
Considerando que o Brasil e muitos outros países tropicais necessitam de aperfeiçoar métodos de recobrimento de taludes, tornam-se necessários estudos que aprimorem a utilização e a eficácia das diferentes alternativas do mercado. Este estudo teve como objetivo avaliar o desempenho das geomantas comerciais antierosivas MacMat ${ }^{\circledR}$, Fibrax $^{\circledR}$ e Tela Biotêxtil ${ }^{\circledR}$ na proteção do solo contra a erosão superficial hídrica. $O$ experimento foi realizado em um talude em corte de estrada na cidade de Viçosa (MG), em meados de 2003, e foi avaliado entre dezembro e março de 2004. Para isso, realizou-se uma análise do escoamento superficial baseada em oito eventos chuvosos comparando-se as variáveis massa de sólidos e volume de suspensão de água + solo escoado em uma combinação de geomantas com ou sem vegetação (mistura de espécies de gramíneas e leguminosas). Os tratamentos testados foram: Tratamento 1 - testemunha (solo exposto); Tratamento 2 - Tela Biotêxtil $^{\circledR}$ com plantas; Tratamento 3 - MacMat $^{\circledR}$ sem plantas; Tratamento 4 MacMat $^{\circledR}$ com plantas; Tratamento 5 - Fibrax ${ }^{\circledR}$ sem plantas; e Tratamento 6 - Fibrax ${ }^{\circledR}$ com plantas. A análise estatística utilizada foi o teste de Tukey a $5 \%$. Embora não tenham sido encontradas diferenças significativas entre os tratamentos aplicados devido ao elevado coeficiente de variação, pode-se constatar que a utilização das mantas proporcionou a redução da perda de solos. O tratamento seis foi o mais
\end{abstract}

\footnotetext{
(1) Parte da Dissertação de Mestrado apresentada à Universidade Federal de Viçosa - UFV. Financiada pelo CNPq e pela Maccaferri do Brasil Ltda. Recebido para publicação em julho de 2008 e aprovado em janeiro de 2009.

(2) Analista de Projetos Especiais II da Fundação Superintendência Estadual de Rios e Lagoas do Estado do Rio de Janeiro SERLA. Campo de São Cristóvão, 138 - $3^{\circ}$ andar, São Cristóvão, CEP 20921-440 Rio de Janeiro (RJ). E-mail: leosifer@gmail.com

${ }^{(3)}$ Professor do Departamento de Engenharia Florestal da Universidade Federal de Viçosa - UFV. Viçosa (MG). E-mail: griffith@ufv.br

(4) Professor do Departamento de Zootecnia, UFV. E-mail: dfonseca@mail.ufv.br

${ }^{(5)}$ Professores do Departamento de Solos, UFV. E-mail: luiz.eduardo@pq.cnpq.br; hruiz@mail.ufv.br
} 
eficiente para impedir a perda de solo. Entretanto, quando esta geomanta foi utilizada sem vegetação (Tratamento 5), permitiu o maior volume de suspensão escoada. Concluiu-se que as geomantas aumentaram a proteção do solo contra a erosão superficial hídrica e a incorporação de vegetação melhorou os resultados em todos os tratamentos.

Termos de indexação: erosão do solo, perda de solos, escoamento superficial, geomanta, talude.

\title{
SUMMARY: EVALUATION OF GEOTEXTILES TO CONTROL SURFACE RUNOFF ON A ROADSIDE
}

\begin{abstract}
Considering that Brazil and many other countries with tropical ecosystems need to enhance methods of embankment cover, it is necessary to study the enhancement of available erosion control means. The study objective was to evaluate the efficiency of three commercial erosion mats: MacMat ${ }^{\circledR}$, Fibrax ${ }^{\circledR}$ and Tela Biotextil ${ }^{\circledR}$ in rainfall surface erosion protection. The experiment was carried out between December 2003 and March 2004 on an embankment of a road section in Viçosa, Minas Gerais State, Brazil. Surface runoff from the experimental area was analyzed based on eight rainfall events and data of the following variables: solid mass and volume of suspended soil + water runoff. These data were compared in relation to geotextiles with or without vegetation (a mixture of grass and legume species). The treatments were:

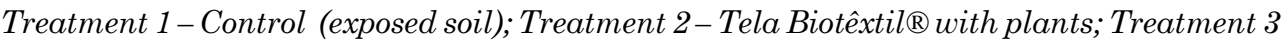
- MacMat ${ }^{\circledR}$ without plants; Treatment 4 - MacMat ${ }^{\circledR}$ with plants; Treatment 5 - Fibrax ${ }^{\circledR}$ without plants and Treatment 6 - Fibrax ${ }^{\circledR}$ with plants. The Tukey test was used at $5 \%$ for the statistical analysis. Although no significant differences were found among treatments due to the high variation coefficient, it was obvious that erosion mats generally reduce soil loss. Treatment 6 was the most efficient. The volume of suspended soil + water runoff was however highest in Treatment 5 (mat without plants). The erosion mats enhanced soil protection against surface erosion by rainwater; vegetation planting along with the mats improved results for all treatments.
\end{abstract}

Index terms: soil erosion, soil loss, runoff, geotextiles, steep slope.

\section{INTRODUÇÃO}

Obras de engenharia em áreas de relevo acidentado, sem obedecer aos critérios técnicos necessários, alteram o comportamento do sistema anteriormente em equilíbrio, gerando situações de risco associadas à instabilidade de taludes e encostas (Toy et al., 2002; Infanti Jr. \& Forsane Filho, 2002).

As principais atividades responsáveis pela acelerada degradação de aspectos geomorfológicos da paisagem são as atividades humanas, como agricultura, mineração, escavações e abertura de estradas (Inbar et al., 1998).

Muitos trabalhos com movimentação de terra (aterros, terraplenagem), como projetos de construção civil, criam taludes íngremes sem vegetação. Estas superfícies ficam sujeitas às intempéries e às flutuações diárias e sazonais de temperatura e umidade, dificultando o estabelecimento de espécies vegetais e comprometendo sua recuperação ambiental (Toy \& Hadley, 1987; Gray \& Sortir, 1996; Cano et al., 2002; Anh et al., 2002; Cunha \& Guerra, 2003). As características dessas feições, em conjunto com suas propriedades físiográficas, predispõem e condicionam diversos fenômenos de dinâmica superficial que incluem movimentos e transporte de massa.

A erosão superficial hídrica, uma das principais formas de perda de solos em ambientes tropicais, é responsável por diferentes danos ambientais em decorrência do transporte de partículas de solo, nutrientes, matéria orgânica, sementes e defensivos agrícolas (Bertoni \& Lombardi Neto, 1990). Este fenômeno leva ao empobrecimento do solo no local de origem da erosão e contaminação, especialmente das águas superficiais (eutrofização e assoreamento), fora do local de origem da erosão (Daniel et al., 1994; Pimentel et al., 1995), gerando consideráveis prejuízos ambientais e econômicos (Bertol et al., 2007). 
Considerando que o Brasil e muitos outros países tropicais necessitam aperfeiçoar métodos de recobrimento de taludes, tornam-se necessários estudos que aprimorem a utilização e a eficácia das diferentes alternativas do mercado para mitigação dos impactos ambientais de superfícies de solo expostas à fenômenos erosivos.

Desta forma, este trabalho visa comparar o comportamento de três produtos geossintéticos combinados com uma cobertura vegetal de gramíneas e leguminosas quanto à sua efetividade no controle da erosão superficial hídrica por meio da contenção experimental planejada de um talude latossólico com exposição do saprolito.

\section{METODOLOGIA}

Este estudo foi realizado no município de Viçosa, na Zona da Mata de Minas Gerais, que integra morfoestruturalmente o domínio dos planaltos cristalinos rebaixados, cujos mantos de alteração profunda situam-se sobre rochas cristalinas datadas do período Pré-Cambriano (IBGE, 1977).

$\mathrm{O}$ relevo da região possui topografia ondulada, variando de suave a forte. A cidade possui uma altitude média de $651 \mathrm{~m}$ e clima úmido com duas estações bem distintas, sendo uma chuvosa, incidente sobre os meses mais quentes (outubro a março), e outra seca, nos meses mais frios (abril a setembro). A média anual da umidade relativa do ar é da ordem de $78 \%$, e a pluviosidade média na faixa de 1.200 a $1.400 \mathrm{~mm}$, com temperaturas variando entre 21,8 e $19,5^{\circ} \mathrm{C}$ (IBGE, 1977; Azevedo, 1999).

$\mathrm{O}$ experimento foi realizado no Campus da Universidade Federal de Viçosa (UFV), Viçosa, MG em um talude côncavo-convexo criado para a construção de um novo acesso ao Campus da UFV, com aproximadamente $122 \mathrm{~m}$ de extensão por $10 \mathrm{~m}$ de comprimento de rampa e declividade média de $112 \%$.

Para a construção do talude, após levantamento planialtimétrico com alocação da via, procedeu-se à limpeza da área com a posterior abertura do espaço projetado para a rodovia. A abertura foi executada mecanicamente com utilização de máquinas para corte e aterro (trator de esteira, escraper, escavadeira hidráulica e compactador pé-de-carneiro). Esse procedimento é rotineiro em obras de terraplenagem de rodovias.

O talude onde foi executado o experimento é integralmente em área de corte. Sua declividade média foi determinada seguindo análise de estabilidade, incluindo a análise da coesão do solo e ensaio de cisalhamento direto.

Por meio de um convênio firmado entre a Universidade Federal de Viçosa (UFV) e a Maccaferri do Brasil, com parceria da Deflor Bioengenharia, foram cedidas as geomantas MacMat ${ }^{\circledR}$, Fibrax ${ }^{\circledR}$ e Tela Biotêxtil ${ }^{\circledR}$ para a execução deste experimento.

A composição básica dos produtos é bastante variada (Tela Fibrax ${ }^{\circledR}(400 \mathrm{BF})$ - um biotêxtil constituído de fibras de coco. As fibras são entrelaçadas por meio de fios de polipropileno formando uma trama resistente, de baixa higroscopicidade e gramatura de $400 \mathrm{~g} \mathrm{~m}^{-2}$; MacMat ${ }^{\circledR}$ - uma manta tridimensional, composta de filamentos grossos de polipropileno, revestidos com negro-de-fumo que retardam sua fotodegradação, gramatura de $500 \mathrm{~g} \mathrm{~m}^{-2}$ e índice de vazios $>90 \%$ e Tela Biotêxtil ${ }^{\circledR}$ - um produto formado com material vegetal fibroso picado (palha), coeso por meio de agregantes orgânicos, translúcido, alta higroscopicidade e com gramatura de $400 \mathrm{~g} \mathrm{~m}^{-2}$ ) e sua fixação no talude foi realizada de acordo com as recomendações dos fabricantes (Maccaferri do Brasil, 2002; Deflor Bioengenharia, 2002).

As variáveis avaliados foram: volume de água escoada e a massa dos sólidos erodidos, em uma combinação de tratamentos que inclui as geomantas com ou sem vegetação (uma combinação de sementes de Brachiaria decumbens, Melinis minutiflora, Stylosanthes guianensis e Cajanus cajan. A taxa de semeadura é de $30 \mathrm{~kg} \mathrm{ha}^{-1}$ ). Desta maneira, os tratamentos analisados foram: Tratamento 1: testemunha (solo exposto); Tratamento 2: Tela Biotêxtil ${ }^{\circledR}$ com plantas; Tratamento 3: MacMat $^{\circledR}$ sem plantas; Tratamento 4: MacMat $^{\circledR}$ com plantas; Tratamento 5: Fibrax ${ }^{\circledR}$ sem plantas; Tratamento 6: Fibrax $^{\circledR}$ com plantas.

O método de implantação do experimento e da coleta dos dados foi uma adaptação dos métodos propostos por Cogo (1978) e Bertoni et al. (1975) conforme as características específicas do experimento, como a localização do talude, declividade e condições para alocação dos coletores.

As unidades amostrais, com dimensão de $8,5 \times 2 \mathrm{~m}$, foram distribuídas na região central do talude para melhor aproveitamento do comprimento de rampa e uniformidade das parcelas experimentais totalizando aproximadamente $530 \mathrm{~m}^{2}$ (Figura 1). As parcelas do tratamento testemunha tiveram suas laterais delimitadas por meio de tiras de chapa de folha de $\mathrm{Zn} \mathrm{n}{ }^{0} 18$, com 11,50 cm para evitar a passagem de material proveniente de outras parcelas.

Na porção inferior de cada parcela, foi instalado um sistema coletor (Figura 2) formado por uma calha coletora em folha de Zn, um balde de plástico (60 L) para armazenamento da suspensão de água e solo escoado - e uma proteção de plástico para a calha, de forma a impedir a entrada de água de chuva no sistema.

A calha coletora (com $10 \mathrm{~cm}$ de altura nas margens por $80 \mathrm{~cm}$ de largura e 90 de comprimento) foi instalada imediatamente abaixo da extremidade inferior da parcela, na porção central, deixando uma 


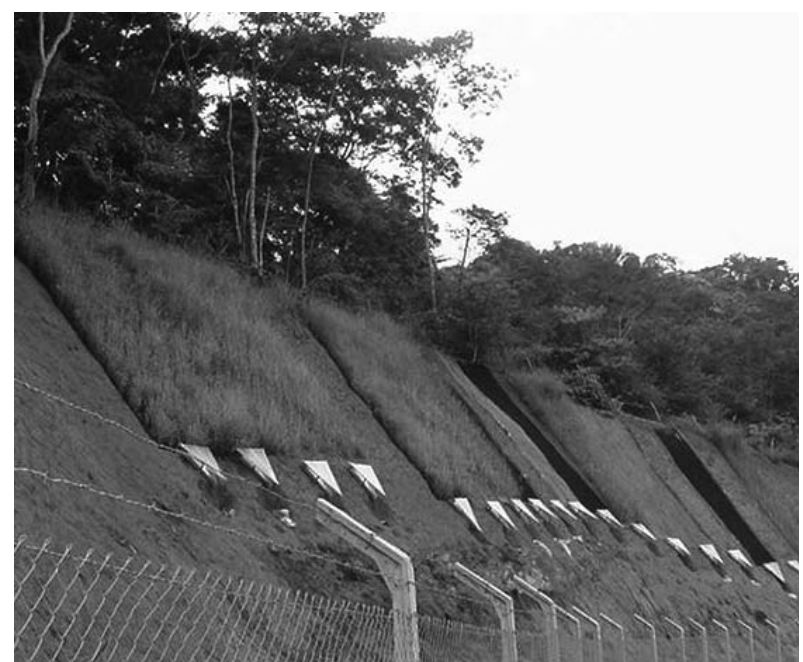

Figura 1. Disposição das parcelas experimentais no talude.

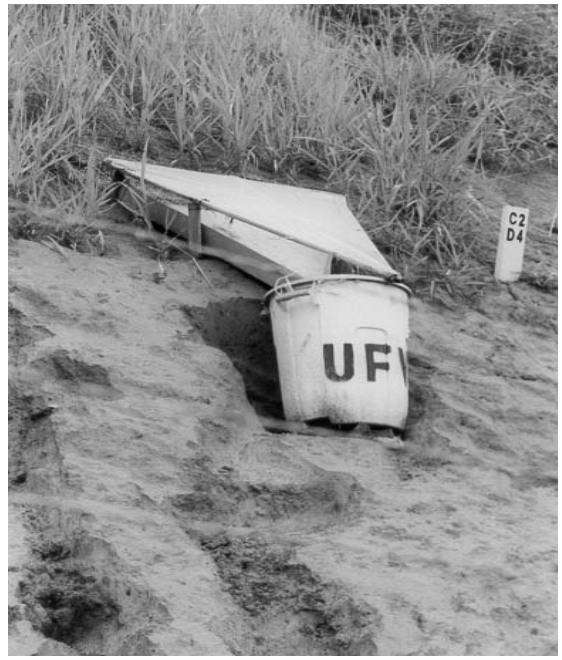

Figura 2. Sistema coletor da suspensão de água + solo escoado.

área de bordadura de $60 \mathrm{~cm}$ de cada lado. As calhas tiveram cerca de $2 \mathrm{~cm}$ de sua extremidade superior dobradas para baixo (formando um ângulo de $90^{\circ}$ ) e enterrada no talude, certificando-se de que todo material escoado fosse dirigido para o balde coletor. Sua fixação foi por meio de três pregos com $10 \mathrm{~cm}$ de comprimento e $1 / 4$ de polegada de diâmetro com parte da extremidade dobrada em "S".

Para a entrada da suspensão de água + solo no coletor, foi aberto um orifício em sua tampa com $10 \mathrm{~cm}$ de diâmetro, coberto com pequenas tiras de plástico, para tentar diminuir a perda de água por evaporação. Os coletores foram colocados no talude em plataformas cavadas no solo.

Dentro de cada coletor foi acoplada uma fita métrica para medir a altura do nível de água + solo escoado para a determinação do volume, calculado indiretamente com base em uma curva de regressão (quadrática) gerada pela calibração do coletor. Como os coletores eram de dois tipos diferentes, as curvas geradas foram:

$$
\begin{aligned}
& \text { Coletor A: Volume }(\hat{y})=1,52-2,03 \sqrt{\mathrm{x}}+1,36 \mathrm{x} \\
& \qquad\left(\mathrm{R}^{2}=0,99\right) \\
& \text { Coletor B: Volume }(\hat{\mathrm{y}})=2,31-2,50 \sqrt{\mathrm{x}}+1,40 \mathrm{x} \\
& \left(\mathrm{R}^{2}=0,99\right)
\end{aligned}
$$

As perdas de água e solo foram medidas após eventos chuvosos ocorridos no período de dezembro de 2003 a março de 2004. Ao todo, foram realizadas 12 coletas, todavia, como a capacidade dos coletores era limitada e houve eventos chuvosos bastante significativos, inevitavelmente o volume de material escoado foi superior à capacidade de armazenamento dos coletores inviabilizando algumas coletas, sendo consideradas, portanto, apenas oito.

A pluviosidade total adotada por coleta foi o somatório das precipitações ocorridas no tempo de exposição dos coletores para cada coleta e a intensidade máxima da chuva em 30 min, a máxima ocorrida no período.

Após a leitura do nível da água dentro do coletor, retirou-se uma amostra de aproximadamente $2 \mathrm{~L}$ (uma garrafa PET) da suspensão homogeneizada de água + solo. As amostras foram encaminhadas ao Laboratório de Física do Solo do Departamento de Solos da UFV para a determinação da massa de sólidos.

Para a análise da massa de sólidos erodidos, as amostras foram deixadas em repouso para decantação por cerca de $24 \mathrm{~h}$. Em seguida, o sobrenadante foi sifonado com mangueira em proveta de $1.000 \mathrm{~mL}$, e o solo mais a água restante foram transferidos para beckers de $500 \mathrm{~mL}$. Volumes conhecidos de água foram adicionados às garrafas $\mathrm{PET}$ para a retirada das partículas aderidas à parede do frasco. Os beckers, previamente tarados, foram então pesados e postos a secar em estufa a $105{ }^{\circ} \mathrm{C}$ com ventilação forçada. $\mathrm{O}$ volume de água da amostra foi calculado por meio da diferença de peso do becker com e sem água. Considerou-se a densidade da água igual a 1 e subtraiuse o "peso" (volume) da água adicionada para retirada das partículas aderidas à parede da garrafa PET. A massa de solo na amostra foi calculada por diferenças de peso, multiplicadas pelo volume total coletado, seguindo regra de três.

Para a comparação dos tratamentos foram realizados contrastes ortogonais do Teste F, sendo eles:

$\mathrm{C}_{1}$ : Tratamento 1 vs Tratamento $2+$ Tratamento $3+$ Tratamento 4 + Tratamento 5 + Tratamento 6 ;

$\mathrm{C}_{2}$ : Tratamento $2 \mathrm{v}_{\mathrm{s}}$ Tratamento $3+$ Tratamento $4+$ Tratamento 5 + Tratamento 6 ;

$\mathrm{C}_{3}$ : Tratamento $3+$ Tratamento $4 \mathrm{v}_{\mathrm{s}}$ Tratamento $5+$ Tratamento 6;

$\mathrm{C}_{4}$ : Tratamento $3 \mathrm{v}_{\mathrm{s}}$ Tratamento 4;

$\mathrm{C}_{5}$ : Tratamento $5 \mathrm{v}_{\mathrm{s}}$ Tratamento 6 . 
O delineamento experimental foi inteiramente casualizado, com três repetições perfazendo um total de 18 parcelas. Os dados foram submetidos à análise de variância com desdobramento das interações significativas e comparação das médias pelo teste de Tukey a $5 \%$, e Dunnette, a $5 \%$ para comparação das testemunhas com os outros tratamentos.

As análises estatísticas foram efetuadas por meio do pacote estatístico SAEG 9.0 (Ribeiro Júnior, 2001).

\section{RESULTADOS E DISCUSSÃO}

As coletas da suspensão água + solo utilizadas nas análises, em ordem cronológica com suas respectivas datas, quantidade e intensidade máxima de chuva em 30 min, podem ser visualizadas no quadro 1.

Quadro 1. Precipitação pluvial e intensidade máxima de chuva para cada coleta, de acordo com dados obtidos para os dias na Estação Meteorológica da Universidade Federal de Viçosa

\begin{tabular}{clrc}
\hline Coleta & \multicolumn{1}{c}{ Data } & $\mathbf{m m}$ & $\mathbf{m m} / \mathbf{3 0}$ \\
\hline 1 & $27 / 01-13 / 02 / 04$ & 116,8 & 20 \\
2 & $23-26 / 02 / 04$ & 60,5 & 40 \\
3 & $27-28 / 02 / 04$ & 10,8 & 10 \\
4 & $02-04 / 03 / 04$ & 28,9 & 8 \\
5 & $06-08 / 03 / 04$ & 1,4 & 7 \\
6 & $10-15 / 03 / 04$ & 12,8 & 1 \\
7 & $16-21 / 03 / 04$ & 28,1 & 3 \\
8 & $22-23 / 03 / 04$ & 61,2 & 20 \\
Total & & 320,5 & \\
\hline
\end{tabular}

A grande variação na intensidade das precipitações teve reflexo direto no volume de suspensão água + solo escoado e massa de sedimentos carreados, variando com os tratamentos aplicados (Quadro 2).

Apesar de o rótulo dos coletores indicar uma capacidade de armazenamento máxima de $60 \mathrm{~L}$, foi comprovada uma capacidade superior conforme se pode observar no quadro 2 , tratamento 4 , coleta 2.

De acordo com os resultados, houve elevada variação nos totais de volume de suspensão água + solo escoado e massa de solo erodido entre os tratamentos analisados (Figura 3).

Este experimento verificou a tendência de redução da erosão com a proteção superficial do solo, como observado em outros trabalhos (Wischmeier \& Smith, 1978; Wildner, 1985; Bertol et al., 1989; Bertoni \& Lombardi Neto, 1990; Carvalho et al., 1990; Braida, 1999; Albuquerque, 2002; Silva et al., 2005), pois, ao se cobrir o solo, impede-se o impacto direto das gotas de chuva, reduzindo sensivelmente a perda pela erosão.

A dissipação da energia cinética do impacto direto das gotas da chuva sobre a superfície diminui a desagregação inicial das partículas de solo e, consequentemente, a concentração de sedimentos na enxurrada, conforme esperado principalmente para as geomantas Fibrax $^{\circledR}$ e Tela biotêxtil ${ }^{\circledR}$ devido sua gramatura e porcentagem de vazios, muito inferior à geomanta MacMat ${ }^{\circledR}$, além de representar um obstáculo mecânico ao livre escoamento superficial da água (Silva et. al., 2005). Apesar disso, não foram detectadas diferenças estatísticas ( $p>0,05)$, à exceção dos Contrastes 2 e 5 (Quadro 3).

Como o aumento da quantidade de água e energia cinética das precipitações está positivamente correlacionado com o aumento da perda de solos (Amorim et al., 2001), coletas subsequentes aos

Quadro 2. Volume de suspensão água + solo escoada e massa de sedimentos carreados em cada tratamento

\begin{tabular}{|c|c|c|c|c|c|c|c|c|}
\hline \multirow{2}{*}{ Tratamento } & \multicolumn{8}{|c|}{ Coleta } \\
\hline & 1 & 2 & 3 & 4 & $\mathbf{5}$ & 6 & 7 & 8 \\
\hline & \multicolumn{8}{|c|}{ Volume de suspensão escoada (L/parcela) } \\
\hline 1 - Solo descoberto & 4,49 & 46,76 & 9,71 & 19,2 & 6,38 & 3,22 & 7,26 & 1,27 \\
\hline 2 - Tela Biotêxtil ${ }^{\circledR}$ & 7,95 & 9,62 & 3,85 & 5,56 & 2,37 & 3,11 & 3,28 & 1,27 \\
\hline 3 - MacMat ${ }^{\circledR}$ sem vegetação & 8,79 & 49,43 & 22,94 & 31,91 & 8,4 & 14,55 & 13,46 & 1,35 \\
\hline 4 - MacMat ${ }^{\circledR}$ com vegetação & 7,46 & 65,81 & 15,04 & 31,36 & 3,35 & 8,88 & 5,28 & 1,17 \\
\hline 5 - Fibrax ${ }^{\circledR}$ sem vegetação & 22,31 & 59,78 & 22,03 & 38,37 & 8,48 & 14,88 & 13,55 & 3,08 \\
\hline \multirow[t]{2}{*}{6 - Fibrax ${ }^{\circledR}$ com vegetação } & 18,65 & 21,32 & 5,96 & 5,19 & 3,12 & 3,57 & 4,96 & 1,35 \\
\hline & \multicolumn{8}{|c|}{ Solo perdido (g/parcela) } \\
\hline 1 - Solo descoberto & 190,16 & 1967,88 & 106,96 & 267,62 & 35,66 & 53,57 & 110,23 & 95,18 \\
\hline 2 - Tela Biotêxtil ${ }^{\circledR}$ & 161,77 & 235,48 & 71,49 & 92,03 & 66,88 & 77,86 & 93,88 & 107,42 \\
\hline 3 - MacMat ${ }^{\circledR}$ sem vegetação & 31,58 & 1272,06 & 199,31 & 861,33 & 14,56 & 108,19 & 31,17 & 62,72 \\
\hline 4 - MacMat ${ }^{\circledR}$ com vegetação & 10,47 & 1032,99 & 57,9 & 42,2 & 0,65 & 34,47 & 1,45 & 7,16 \\
\hline 5 - Fibrax ${ }^{\circledR}$ sem vegetação & 19,98 & 61,89 & 9,62 & 21,65 & 1,98 & 7,12 & 6,02 & 12,81 \\
\hline 6 Fibrax $^{\circledR}$ com vegetação & 3,22 & 4,23 & 1,03 & 1,13 & 0,58 & 0,97 & 0,8 & 2,14 \\
\hline
\end{tabular}



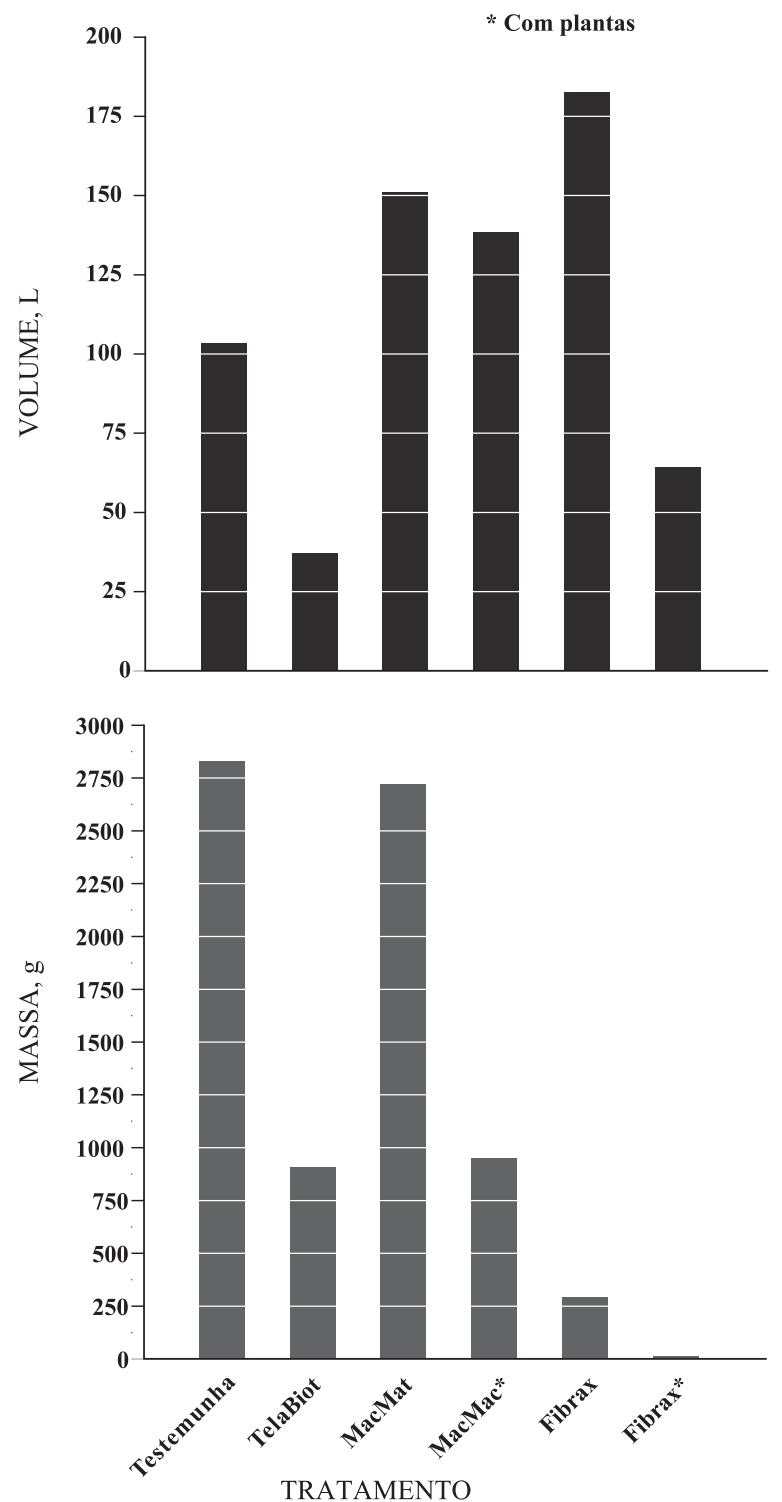

Figura 3. Totais de volume acumulado de suspensão água + solo escoado e massa de solo perdida por tratamento.

eventos chuvosos mais intensos tenderam a elevar os valores médios de sólidos erodidos, que, associados a pequenas variações na superfície do solo na crista do talude, intensificaram a concentração diferencial do fluxo superficial de água em direção a uma das parcelas do tratamento 3 .

O elevado volume de suspensão água + solo escoado no tratamento 3 também pode ser atribuído à forma e propriedade do material que o constitui. Conforme observado em campo, a disposição dos fios (polipropileno), por não impedir completamente o impacto direto das gotas de chuva na superfície, facilita a formação de crostas estruturais, deposicionais e erosionais na superfície do solo (Valentin \& Bresson, 1992; Brandão et al., 2007), bem como filmes de água que obstruem a infiltração, consequentemente aumentando o fluxo superficial que se dá sob e sobre a manta.

Quanto à massa de sólidos erodidos, o tratamento 6 foi o mais efetivo para o controle da perda de solos. O tratamento 5 foi o que gerou maior volume de suspensão água + solo escoado, contrastando com o tratamento 4, que, devido à sua composição com fibras vegetais desidratadas e hidrofílicas - colmos de capim - e à disposição dessas fibras na manta, facilitou maior porosidade na superfície do solo e infiltração de água no perfil. O valor elevado do volume de suspensão escoada para o tratamento 5 é atribuído à densidade de fibras e à sua baixa hidrofilia, incorrendo na formação do escoamento superficial sobre a manta. Por outro lado, esta disposição, além de impedir o impacto direto das gotas de chuva no solo, funciona como um elemento filtrante dos sedimentos transportados.

Os tratamentos 3 e 4 não demonstraram contribuição considerável para a redução do volume de suspensão de água + solo escoada em comparação com a testemunha. Especula-se que isso se deva à concentração diferencial de água na crista do talude e ao próprio método indicado pelo fabricante, que sugere a aplicação da mistura de solo + sementes sobre a manta. Desta maneira, principalmente nos eventos chuvosos anteriores ao estabelecimento da vegetação, esta mistura inevitavelmente foi direcionada para os coletores, contribuindo assim para maior volume de solo erodido. Entretanto, o tratamento 4 possibilitou uma redução no total de solo erodido, evidenciando a influência positiva da vegetação (Figura 3).

Apesar das precauções tomadas no preparo do terreno para a implementação do experimento suavização das deformidades da face do talude e verificação de uma calha de drenagem na crista - os

Quadro 3. Contrastes ortogonais do volume de suspensão de água + solo escoada e dos sólidos erodidos comparando-se os tratamentos aplicados

\begin{tabular}{|c|c|c|c|c|c|}
\hline Tratamento & C1 & $\mathrm{C} 2$ & C3 & $\mathrm{C} 4$ & C5 \\
\hline 1 - Testemunha & 5 & 0 & 0 & 0 & 0 \\
\hline 2 - Tela Biotêxtil & -1 & 4 & 0 & 0 & 0 \\
\hline 3- MacMat & -1 & -1 & 1 & 1 & 0 \\
\hline 4- MacMat com Plantas & -1 & -1 & 1 & -1 & 0 \\
\hline 5 - Fibrax & -1 & -1 & -1 & 0 & 1 \\
\hline 6 - Fibrax com Plantas & -1 & -1 & -1 & 0 & -1 \\
\hline & \multicolumn{4}{|c|}{ Contrastes Ortogonais } & nais \\
\hline Todas as coletas & \multicolumn{2}{|c|}{ ns 364,1341} & & $\begin{array}{c}\text { ns } \\
\text { cela }\end{array}$ & 120,1094 \\
\hline Todas as coletas & $\mathrm{ns}$ & ns & ns & $\mathrm{ns}$ & ns \\
\hline
\end{tabular}

ns: não-significativo, a $5 \%$, pelo teste de Tukey. 
problemas encontrados contribuíram sobremaneira para a elevação do coeficiente de variação, influenciando negativamente a sensibilidade da análise estatística, além das próprias características físico-químicas diferenciadas no perfil do solo como reportadas por Carvalho Filho (1989) e Nunes (1999) em perfis de solo no Campus de Viçosa. Dessa maneira, torna-se necessário chamar a atenção para o cuidado imprescindível no controle das variáveis ambientais que possam interferir nas unidades experimentais e comprometer estudos desta natureza.

Conforme salientado neste estudo, não houve concomitância entre a perda de água pelo escoamento superficial e a perda de solos com a utilização desses produtos. Alguns trabalhos demonstram que a eficácia de redução das perdas de solo por erosão hídrica pode ser quase completa com a proteção superficial do solo, porém é relativamente menos eficaz e muito variada em relação à redução das perdas de água (Bertol et al., 1997; Schick et al., 2000; Cogo et al., 2003).

Muito embora as diferenças estatísticas não sejam significativas, observou-se que os tratamentos com vegetação tiveram resultados mais favoráveis para o controle da erosão superficial hídrica que os tratamentos sem vegetação.

\section{CONCLUSÕES}

1. Os produtos para controle da erosão utilizados na pesquisa foram eficientes no controle da erosão do solo quando comparados com o testemunha.

2. A perda de solos e o volume de água escoada não foram concomitantes. O tratamento com maior perda de solo (testemunha) não foi o que apresentou maior volume de suspensão escoada.

3. O tratamento com a Tela Biotêxtil ${ }^{\circledR}$ foi a que melhor reduziu o volume de suspensão de água escoada, apresentando maior infiltração e consequente percolação de água.

4. Os resultados obtidos nesta pesquisa evidenciaram a importância da proteção de taludes de cortes de estrada em razão da significativa quantidade de sedimentos que são carreados pela erosão.

\section{LITERATURA CITADA}

ALBUQUERQUE, A.W.; LOMBARDI NETO, F.; SRINIVASAN, V.S. \& SANTOS, J.R. Manejo da cobertura do solo e de práticas conservacionistas nas perdas de água e solo em Sumé, PB. R. Bras. Eng. Agríc. Amb., 6:136-141, 2002.

AMORIM, R.S.S.; SILVA, D.S.; PRUSKI, F.F. \& MATOS, A.T. Influência da declividade do solo e da energia cinética de chuvas simuladas no processo de erosão entre sulcos. R. Bras. Eng. Agríc. Amb., 5:124-130, 2001.
ANH, T.B.; CHO, S.D. \& YANG, S.C. Stabilization of soil slope using geosynthetic mulching mat. Geotext.Geomembr., 20:135-146, 2002.

AZEVEDO, M.A.A. Contribuição ao estudo geotécnico de solos de Viçosa-MG. Viçosa, MG, Universidade Federal de Viçosa. 1999. 169 p. (Tese de Mestrado)

BERTOL, I.; COGO, N.P. \& LEVIEN, R. Cobertura morta e métodos de preparo do solo na erosão hídrica em solo com crosta superficial. R. Bras. Ci. Solo, 13:373-379, 1989.

BERTOL, I.; COGO, N.P. \& LEVIEN, R. Erosão hídrica em diferentes preparos do solo logo após as colheitas de milho e trigo, na presença e na ausência dos resíduos culturais. R. Bras. Ci. Solo, 21:409-418, 1997.

BERTOL, I.; COGO, N.P.; SCHICK, J.; GUDAGNIN, J.C. \& AMARALA, A.J. Aspectos financeiros relacionados às perdas de nutrientes por erosão hídrica em diferentes sistemas de manejo do solo. R. Bras. Ci. Solo, 31:133-142, 2007.

BERTONI, J. \& LOMBARDI NETO, F. Conservação do solo. São Paulo, Ícone, 1990. 392p.

BERTONI, J.; LOMBARDI NETO, F. \& BENATTI JR., R. Metodologia para a determinação de perdas por erosão. Campinas, Instituto Agronômico de Campinas, 1975. 14p. (Circular, 44)

BRAIDA, J.A. \& CASSOL, E.A. Relações da erosão em entressulcos com o tipo e com a quantidade de resíduo vegetal na superfície do solo. R. Bras. Ci. Solo, 23:711721,1999

BRANDÃO, V.S.; SILVA, D.D.; RUIZ, H.A.; PRUSKI, F.F.; SCHAEFER, C.E.G.R.; MARTINEZ, M.A. \& SILVA, E.O Perdas de solo e caracterização física e micromorfológica de crostas formadas em solos sob chuva simulada. Eng. Agríc., 27:129-138, 2007.

CANO, A.; NAVIA, R.; AMEZAGA, I. \& MONTALVO, J. Local topoclimate effect on short-term cutslope reclamation success. Ecol. Eng., 18:489-498, 2002.

CARVALHO, F.L.C.; COGO, N.P. \& LEVIEN, R. Eficácia relativa de doses e formas de manejo do resíduo cultural de trigo na redução da erosão hídrica do solo. R. Bras. Ci. Solo, 14:227-234, 1990.

CARVALHO FILHO, A. Caracterização mineralógica, química e física de solos de duas unidades de paisagem do planalto de Viçosa. Viçosa, MG, Universidade Federal de Viçosa, 1989. 114p. (Tese de Mestrado)

COGO, N.P. Uma contribuição à metodologia de estudo das perdas de erosão em condições de chuva natural. I. Sugestões gerais, medição dos volumes, amostragem e quantificação de solo e água da enxurrada (1 aproximação). In: ENCONTRO NACIONAL DE PESQUISA SOBRE CONSERVAÇÃO DO SOLO, 2., Passo Fundo, 1978. Anais. Passo Fundo, Embrapa/CNPT, 1978. p.75-98.

COGO, N.P.; LEVIEN, R. \& SCHWARZ, R.A. Perda de solo e água por erosão hídrica influenciadas por métodos de preparo, classes de declive e níveis de fertilidade do solo. R. Bras. Ci. Solo, 27:743-753, 2003. 
CUNHA, S.B. \& GUERRA, A.J.T. Degradação ambiental. In: GUERRA, A.J.T. \& CUNHA, S.B., eds. Geomorfologia e meio ambiente. 4.ed. Rio de Janeiro, Bertrand Brasil, 2003. p.337-379.

DANIEL, T.C.; SCHARPLEY, A.N.; EDWARDS, D.R.; WEDEPOHL, R. \& LEMUNYON, J.L. Minimizing surface water eutrophication from agriculture by phosphorus management. J. Soil Water Conserv., 40:30-38, 1994.

DEFLOR BIOENGENHARIA. Soluções ambientais definitivas. Belo Horizonte, 2002. 31p. (Catálogo)

GRAY, D.H. \& LEISER, A.T. Biotechnical slope protection and erosion control. New York, Van Nostrand Reinhold, 1989. $217 \mathrm{p}$

GRAY, D.H. \& SORTIR, R.B. Biotechnical and soil bioengineering slope stabilization: A pratical guide for erosion control. New York, John Wiley \& Sons, 1996. 378 .

INSTITUTO BRASILEIRO DE GEOGRAFIA E ESTATÍSTICA - IBGE. Geografia do Brasil: Região sudeste. Rio de Janeiro, 1977. p.1-43.

INBAR, M.; TAMIR, M. \& WITTENBERG, L. Runoff and erosion process after a forest fire in Mount Carmel, a Mediterranean area. Geomorphology, 24:17-33, 1998.

INFANTI JR., N. \& FORSANE FILHO, N.F. Processos de dinâmica superficial. In: OLIVEIRA, A.M.S. \& BRITO, S.N.A., eds. Geologia de engenharia. São Paulo, Associação Brasileira de Geologia de Engenharia, 1998. p.131-152.

MACCAFERRI DO BRASIL LTDA. Revestimento de taludes: Necessidades e soluções. Jundiaí, 2002. 15p.

NUNES, W.A.G.A. Caracterização física, química, mineralógica, micromorfológica e espectral de alguns solos da zona de planalto mineira. Viçosa, MG, Universidade Federal de Viçosa, 1999. 135p. (Tese de Mestrado)
PIMENTEL, D.; HARVEY, C.; RESOSUDARMO, P.; SINCLAIR, K.; KURZ, D.; McNAIR, M.; CRIST, S.; SHPRITZ, L.; FITTON, L.; SAFFOURI, R. \& BLAIR, R. Environmental and economic costs of soil erosion and conservation benefits. Science, 267:1117-1123, 1995.

RIBEIRO JÚNIOR, J.L. Análises estatísticas no SAEG. Viçosa, MG, Folha de Viçosa, 2001. 301p.

SCHICK, J.; BERTOL, I.; BATISTELA, O. \& BALBINOT JR., A.A. Erosão hídrica em Cambissolo Húmico alumínico submetido a diferentes sistemas de preparo e cultivo do solo: I. Perdas de solo e água. R. Bras. Ci. Solo, 24:427436, 2000.

SILVA, D.D.; PRUSKI, F.F.; SCHAEFER, C.E.G.R.; AMORIM, R.S.S. \& PAIVA, K.W.N. Efeito da cobertura nas perdas de solo em um Argissolo Vermelho-Amarelo utilizando simulador de chuva. Eng. Agríc., 25:409-419, 2005.

TOY, T.J.; FOSTER, G.R. \& RENARD, K.G. Soil erosion: Processes, prediction, measurement, and control. New York, John Wiley \& Sons, 2002. 338p.

TOY, T.J. \& HADLEY, R.F. Geomorphology and reclamation of disturbed lands. Orlando, Academic Press, 1987. 480p.

VALENTIN, C. \& BRESSON, L.M. Morphology, genesis and classification of surface crusts in loamy and sandy soils. Geoderma, 55:225-45, 1992.

WILDNER, L.P. Efeito da adição de diferentes resíduos orgânicos nas perdas de solo e água em um solo Podzólico Vermelho-Amarelo. Santa Maria, Universidade Federal de Santa Maria, 1985. 100p. (Tese de Mestrado)

WISCHMEIER, W.H. \& SMITH, D.D. Predicting rainfall erosion losses: A guide to conservation planning. Washington, USDA, 1978. 58p. (Agricultural Handbook, 573) 